\title{
Cumulative oxygen deficit is a novel predictor for the timing of invasive mechanical ventilation in COVID-19 patients with respiratory distress
}

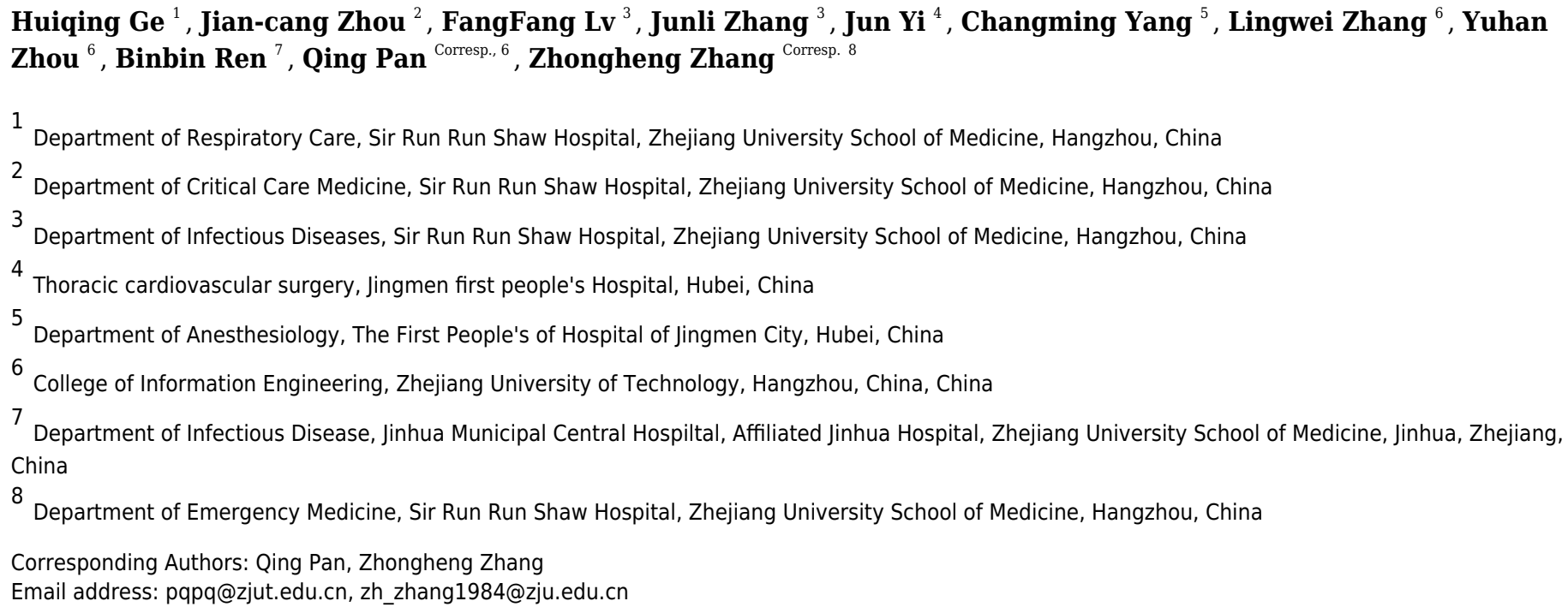

Background and objectives: The timing of invasive mechanical ventilation (IMV) is controversial in COVID-19 patients with acute respiratory hypoxemia. The study aimed to develop a novel predictor called cumulative oxygen deficit (COD) for the risk stratification. Methods: The study was conducted in four designated hospitals for treating COVID-19 patients in Jingmen, Wuhan, from January to March 2020. COD was defined to account for both the magnitude and duration of hypoxemia. A higher value of COD indicated more oxygen deficit. The predictive performance of COD was calculated in multivariable Cox regression models. Results: A number of 111 patients including 80 in the non-IMV group and 31 in the IMV group were included. Patients with IMV had substantially lower $\mathrm{PaO}_{2}(62$ $(49,89)$ vs. $90.5(68,125.25) \mathrm{mmHg} ; \mathrm{p}<0.001)$, and higher COD $(-6.87(-29.36,52.38)$ vs. $-231.68(-1040.78,119.83) \mathrm{mmHg}$.day) than patients without IMV. As compared to patients with COD $<0$, patients with COD $>30 \mathrm{mmHg}$.day had higher risk of fatality (HR: $3.79,95 \%$ $\mathrm{Cl}: 2.57$ to $16.93 ; p=0.037$ ), and those with COD $>50 \mathrm{mmHg}$.day were 10 times more likely to die (HR: $10.45,95 \% \mathrm{Cl}: 1.28$ to $85.37 ; p=0.029$ ). Conclusions: The study developed a novel predictor COD which considered both magnitude and duration of hypoxemia, to assist risk stratification of COVID-19 patients with acute respiratory distress. 


\section{Cumulative oxygen deficit is a novel predictor for the}

\section{2 timing of invasive mechanical ventilation in COVID-19}

4 Huiqing Ge (MD)

5 Department of Respiratory Care, Sir Run Run Shaw Hospital, Zhejiang University School of

6 Medicine, Hangzhou, China. Email: netghq@zju.edu.cn

7 Jian-cang Zhou (MD)

8 Department of Critical Care Medicine, Sir Run Run Shaw Hospital, Zhejiang University School

9 of Medicine, Hangzhou, China. Email: jiancangzhou@zju.edu.cn

10 FangFang Lv (MD)

11 Department of Infectious Diseases, Sir Run Run Shaw Hospital, Zhejiang University School of

12 Medicine, Hangzhou, China. Email: lvfangfang@zju.edu.cn

13 Junli Zhang (MD)

14 Department of Infectious Diseases, Sir Run Run Shaw Hospital, Zhejiang University School of

15 Medicine, Hangzhou, China. Email: sky0418happy@163.com

16 Jun Yi (MD)

17 Thoracic cardiovascular surgery, Jingmen first people's Hospital, Hubei, China. email:

18 215487150@qq.com

19 Changming Yang (MD)

20 Department of Anesthesiology, The First People's of Hospital of Jingmen City, Hubei, China.

21 Email: 627126765@qq.com 
22 Lingwei Zhang (MS)

23 College of Information Engineering, Zhejiang University of Technology, Hangzhou, China.

24 Email: 1510643057@qq.com

25 Yuhan Zhou (MS)

26 College of Information Engineering, Zhejiang University of Technology, Hangzhou, China.

27 Email: 1095303450@qq.com

28 Binbin Ren (MD)

29 Department of Infectious Disease, Jinhua Municipal Central Hospiltal, Affiliated Jinhua

30 Hospital, Zhejiang University School of Medicine, Jinhua City, Zhejiang Province, China.

31 Email: renb105@163.com

32 Qing Pan $(\mathrm{PhD})$,

33 College of Information Engineering, Zhejiang University of Technology, Hangzhou, China.

34 Email: pqpq@zjut.edu.cn

35 Zhongheng Zhang (MD)

36 Department of Emergency Medicine, Sir Run Run Shaw Hospital, Zhejiang University School of

37 Medicine, Hangzhou, China.

38 Corresponding to:

39 Zhongheng Zhang

40 Address: No 3, East Qingchun Road, Hangzhou 310016, Zhejiang Province, China.

41 Email: zh_zhang1984@zju.edu.cn

42 Qing Pan,

43 College of Information Engineering, Zhejiang University of Technology, 310023, Hangzhou,

44 China. Email: pqpq@zjut.edu.cn

$45 \quad$ Funding 
46 BR received funding from the Public Research Project of Emergency Prevention and Treatment

47 of COVID-19 of Jinhua City (2020XG-06); JZ received funding from Major Science and

48 Technology Project of Zhejiang Province Health Commission (WKJ-ZJ-2112). 
51 Background and objectives: The timing of invasive mechanical ventilation (IMV) is

52 controversial in COVID-19 patients with acute respiratory hypoxemia. The study aimed to 53 develop a novel predictor called cumulative oxygen deficit (COD) for the risk stratification.

54 Methods: The study was conducted in four designated hospitals for treating COVID-19 patients 55 in Jingmen, Wuhan, from January to March 2020. COD was defined to account for both the 56 magnitude and duration of hypoxemia. A higher value of COD indicated more oxygen deficit.

57 The predictive performance of COD was calculated in multivariable Cox regression models.

58 Results: A number of 111 patients including 80 in the non-IMV group and 31 in the IMV group

59 were included. Patients with IMV had substantially lower $\mathrm{PaO}_{2}(62(49,89)$ vs. $90.5(68,125.25)$

$60 \mathrm{mmHg} ; \mathrm{p}<0.001)$, and higher COD (-6.87 (-29.36, 52.38) vs. $-231.68(-1040.78,119.83)$

$61 \mathrm{mmHg} \cdot$ day) than patients without IMV. As compared to patients with COD $<0$, patients with

$62 \mathrm{COD}>30 \mathrm{mmHg} \cdot$ day had higher risk of fatality (HR: 3.79, 95\% CI: 2.57 to $16.93 ; \mathrm{p}=0.037)$,

63 and those with COD $>50 \mathrm{mmHg} \cdot$ day were 10 times more likely to die (HR: $10.45,95 \% \mathrm{CI}$ :

641.28 to $85.37 ; \mathrm{p}=0.029)$.

65 Conclusions: The study developed a novel predictor COD which considered both magnitude and 66 duration of hypoxemia, to assist risk stratification of COVID-19 patients with acute respiratory 67 distress. 


\section{Introduction}

71 Coronavirus disease 2019 (COVID-19) has spread all over the world since its first outbreak in

72 Wuhan, China in December 2019 (Wang et al., 2020; Novel Coronavirus Pneumonia Emergency

73 Response Epidemiology Team, 2020). The fatality rate was reported to be around 5\% all over the

74 world (Phua et al., 2020). A substantial number of patients (19\%) infected with the severe acute

75 respiratory syndrome coronavirus 2 (SARS-CoV-2) will develop respiratory distress and acute

76 lung injury (Wu \& McGoogan, 2020; Ruan et al., 2020). Respiratory support becomes important

77 for this type of severe patients (Yang et al., 2020). The surviving sepsis guideline of critically ill

78 COVID-19 patients recommended use of oxygen supplementation to maintain pulse oximetry $>$

$7990 \%$, followed by non-invasive mechanical ventilation (NIV), high-flow nasal canula (HFNC),

80 invasive mechanical ventilation (IMV) and extracorporeal membrane oxygenation (ECMO).

81 However, there is no specific recommendations for the timing of transition from non-invasive

82 support to IMV, and the recommendations are largely based on expert opinions. For example, the

83 guideline recommends "close monitoring for worsening of respiratory status, and early

84 intubation in a controlled setting if worsening occurs" (Alhazzani et al., 2020). This

85 recommendation is based on best practice statement and there is no data on when IMV should be

86 initiated. In clinical practice, the judgement of "worsening" is subjective and varied substantially

87 between different institutions and physicians. The timing of initiation of IMV is not standardized

88 and is mainly determined by subjective judgement. On the one hand, IMV is able to reverse

89 catastrophic hypoxemia and maintain tissue oxygenation, which is life-saving for COVID-19

90 patients with severe hypoxemia. On the other hand, IMV can cause ventilator-induced lung

91 injury (Herasevich et al., 2011; Cressoni et al., 2016), and patients on IMV usually require large

92 dose of sedatives, analgesics and even neuromuscular blockades (Jakob et al., 2012; Bellani et 
93 al., 2016; Chang et al., 2020). These drugs have significant adverse effects (Barr et al., 2013;

94 Murray et al., 2016). Thus, it is difficult to determine the appropriate timing of IMV.

95 In our experience, we proposed that the timing of transition from non-invasive oxygenation to

96 IMV should consider both the magnitude of hypoxemia and the duration of the hypoxemia. Thus,

97 we developed a novel marker called Cumulative Oxygen Deficit (COD) to reflect both

98 dimensions. By using a single predictor, we reduce a two-dimension feature to a one-dimension

99 parameter that is comparable among different patients. In our study, we hypothesized that the

100 COD before IMV could be a better biomarker than $\mathrm{PaO}_{2}$ to predict survival outcome.

101

102 
104 Methods

105 Study design and setting

106 The study was conducted in four designated hospitals for treating COVID-19 patients in

107 Jingmen, Wuhan, from January to March 2020. Medical records were retrospectively reviewed

108 to identify eligible patients and variables. Laboratory tests and type of ventilation support were

109 recorded as longitudinal data. The study was designed as a longitudinal study that all patients

110 were followed until hospital discharge or death. One subject contributed several observation

111 units. Patients were divided into groups with IMV and without IMV during hospitalization. The

112 study was approved by the ethics committee of the First People's hospital of Jingmen (Approval

113 number: 202002007) and the ethics committee of Sir Run Run Shaw hospital (20200407-32).

114 Individual patient data were de-identified before analysis. Informed consent was waived as

115 determined by the IRB due to retrospective nature of the study design in accordance to the local

116 regulations.

117 Study population

118 COVID-19 was confirmed by either 1) genetic sequencing showed highly homogenous sequence

119 with the known novel coronavirus; or 2) novel coronavirus nucleic acid was positive as

120 confirmed by real time (RT)-PCT in respiratory or blood specimen (Jin et al., 2020; Alhazzani et

121 al., 2020). All patients with respiratory distress with one of the following criteria were eligible:

122 respiratory rate $>30 / \mathrm{min}$, or oxygen saturation $\leq 93 \%$, or $\mathrm{PaO} 2 / \mathrm{FiO} 2$ ratio $\leq 300 \mathrm{mmHg}$. We

123 screened medical records on admission and identified patients with pulse oximetry $\leq 93 \%$ on

124 room air and requires oxygen therapy (OT). Exclusion criteria included: 1) patients with chronic

125 obstructive pulmonary disease with baseline pulse oximetry $<92 \%$; 2) pregnant women; 3) 
126 subjects younger than 18 years old; 4) patients with do-not-resuscitate order; and 5) patients with

127 comorbidities such as severe burn, recent major stroke with paralysis, terminally ill malignancy,

128 immunodeficiency and dialysis-dependent renal failure.

129 Clinical variables

130 Demographics such as age and sex were recorded. Comorbidities were recorded in broad

131 categories such as those involving respiratory system and cardiovascular system. The smoking

132 history were extracted from the medical records. All laboratory variables were recorded in a

133 longitudinal manner. These included serum lactate, arterial partial oxygen pressure $\left(\mathrm{PaO}_{2}\right)$,

134 arterial partial pressure of carbon dioxide $\left(\mathrm{PaCO}_{2}\right)$, base excess $(\mathrm{BE}), \mathrm{pH}, \mathrm{C}$-reactive protein

135 (CRP), Lymphocyte count, and fraction of inspired oxygenation (FiO2) were extracted.

136 Respiratory support included OT, NIV, HFNC, IMV and ECMO. The transition time from one

137 type to another was recorded to create a number of time intervals at which a subject was on a

138 specific type of respiratory support. Laboratory variables were then matched to each time

139 interval by their respective measurement time. This created a dataset of counting process that

140 included the start time and end time for an interval.

141 Clinical outcomes included vital status at hospital discharge, length of stay in the hospital were

142 recorded.

143 Calculation of cumulative oxygen deficit (COD)

144 For patients with IMV, COD was calculated before the use of IMV. Figure 1 is a sample patient

145 used to illustrate the calculation of COD: $\operatorname{COD}(\mathrm{mmHg} \cdot$ day $)=80 \times\left(t_{5}-t_{1}\right)-$

$146 \sum_{i=1}^{4}\left(x_{i+1}+x_{i}\right) \cdot\left(t_{i+1}-t_{i}\right) / 2$, where $x_{i}$ is the value of $\mathrm{PaO}_{2}$ measured in $\mathrm{mmHg}$, and $t_{i}$ is the

147 time at which $x_{i}$ is measured. The low end value of $\mathrm{PaO}_{2}$ was $80 \mathrm{mmHg}$ in our hospital and this

148 value is also physiologically reasonable that the oxygen saturation will not continue to rise above 
149 this reference value (Collins et al., 2015). Thus, the COD accounted for both magnitude and

150 duration of hypoxemia before IMV. We hypothesized that the longer a patient was on hypoxemia

151 before IMV, the worse of the survival outcome. On the other hand, the outcome would be not so

152 bad if hypoxemia was immediately corrected with IMV even if the magnitude of hypoxemia is

153 large.

154 Statistical analysis

155 Demographic and laboratory data were compared between patients with and without IMV.

156 Quantitative data were first tested for normality by using the Kolmogorov-Smirnov (K-S)

157 normality test. Normal data were expressed as mean and standard deviation and were compared

158 between groups with t test. Non-normally distributed data were expressed as median and

159 interquartile range (IQR) and were compared with Wilcoxon Rank Sum test. Categorial variables

160 were expressed as the number and percentage and were compared using chi-square or Fisher's

161 exact test if appropriate (Zhang et al., 2017).

162 Alluvial plot was employed to visualize how patients transitioned from different types of

163 respiratory support over time. In patients with IMV, we created multivariable Cox regression

164 model to explore the independent predictors of survival outcome. The COD was categorized into

165 four categories at cutoff values of 0,30 and $50 \mathrm{mmHg} \cdot$ day. A COD value of $30 \mathrm{mmHg} \cdot$ day is

166 equivalent to $60 \mathrm{mmHg}$ for 1.5 days, and a negative value indicates no oxygen deficit. Other

167 variables such as time from admission to $\mathrm{IMV}, \mathrm{PaO}_{2}, \mathrm{PaCO}_{2}$, Lactate, lymphocyte count, CRP

168 and BE were adjusted for in the model. These variables were included in multivariable

169 regression model because they were considered to be confounders by domain expertise and/or

170 univariate analysis with $\mathrm{p}<0.2$. The predictive performance of COD was compared with $\mathrm{PaO} 2$

171 before intubation and the time from admission to intubation. We reported time-dependent AUC 
172 for the discriminations from day 7 to 28 after hospital admission (Kamarudin, Cox \&

173 Kolamunnage-Dona, 2017).

174 All statistical analyses were performed using RStudio (Version 1.1.463; R version: 4.0.0).

175 Results

176 Study population

177 A total of 111 patients met the inclusion criteria and were included for analysis. No patients were

178 excluded due to COPD, pregnancy CVA and paralysis. There was no patient being excluded

179 from the participating hospitals. There were 80 patients who did not need IMV, and 31 patients

180 required IMV during hospitalization. Patients with IMV had substantially lower $\mathrm{PaO}_{2}$ (62 (49,

181 89) vs. $90.5(68,125.25) \mathrm{mmHg} ; \mathrm{p}<0.001)$, higher $\mathrm{pH}(7.44(7.38,7.47)$ vs. $7.40(7.35,7.43) ; \mathrm{p}$

$182=0.006)$, higher serum lactate $(2.5(1.7,3.1)$ vs. $1.7(1.1,2.85) \mathrm{mmol} / \mathrm{L}, \mathrm{p}<0.036)$ and higher

183 COD $(-6.87(-29.36,52.38)$ vs. $-231.68(-1040.78,119.83) \mathrm{mmHg} \cdot$ day) than patients without

184 IMV during hospitalization (Table 1). These variables were reported as the first value during

185 hospitalization. The time courses of the transition from different types of respiratory support are

186 shown in Figure 2. It is noted that larger proportion of patients required IMV in the non-

187 survivors.

188 Independent association of COD and survival outcome in IMV patients

189 COD was independently associated with survival outcome in multivariable Cox regression

190 model. As compared to patients with COD $<0$, patients with COD from 0 to $30 \mathrm{mmHg} \cdot$ day

191 were not more likely to die, whereas those with COD $>30 \mathrm{mmHg} \cdot$ day had higher risk of

192 fatality (HR: $3.79,95 \% \mathrm{CI}: 2.57$ to $16.93 ; \mathrm{p}=0.037$ ), and those with COD $>50 \mathrm{mmHg} \cdot$ day

193 were 10 times more likely to die (HR: $10.45,95 \% \mathrm{CI}: 1.28$ to $85.37 ; \mathrm{p}=0.029)$. The time from 
194 admission to intubation, $\mathrm{PaO} 2$ and lymphocyte count were not associated with survival outcome

195 (Table 2). The time-dependent AUCs of COD, $\mathrm{PaO} 2$ and the time from admission to intubation

196 are shown in Figure 3. It showed that COD had consistently higher AUCs from day 14 to 21. In

197 other words, COD was the best predictor after day 14. Table 3 shows factors associated with 198 IMV.

199 Discussion

200 The study developed a novel biomarker COD which considered both magnitude and duration of

201 hypoxemia, to assist the timing of IMV in patients with COVID-19. In patients with IMV during

202 hospitalization, COD before intubation was a strong predictor of survival outcome. Patients with

$203 \mathrm{COD}>30 \mathrm{mmHg} \cdot$ day, which is equivalent to a persistent hypoxemia with $\mathrm{PaO}_{2}$ of $60 \mathrm{mmHg}$

204 for 1.5 days, are more likely to die during hospitalization. Patients in crowded hospital during

205 COVID-19 pandemic were more likely to experience this situation. The time dependent AUCs of 206 COD were substantially higher than that of the $\mathrm{PaO}_{2}$ or the time from admission to intubation

207 alone. Clinical implication of this finding is that we need to consider both the magnitude and

208 duration of hypoxemia before IMV is considered. Long duration of mild hypoxemia, which is

209 prevalent in clinical practice under NIV, may be dangerous for COVID-19 patients.

210 Many studies have been conducted to address the question on whether NIV should be used for

211 patients with pulmonary/direct ARDS, but the results are conflicting (Chawla et al., 2020). NIV

212 was not associated with improved mortality or length of stay, compared with patients who were

213 intubated without trying NIV in a cohort of Middle East Respiratory Syndrome (MERS) patients.

214 Furthermore, most patients $(92.4 \%)$ who had tried NIV were eventually managed with

215 IMV(Alraddadi et al., 2019). However, this was a retrospective study and the initiation of IMV 
216 was not standardized prospectively. Our study indicated that large COD can be harmful and the

217 correction of COD with IMV might be beneficial. This could be explained by potential adverse

218 effects of NIV including large tidal volumes and injurious transpulmonary pressures (Brochard et

219 al., 2014). These adverse effects of NIV could be avoided by using IMV. For example, protective

220 ventilation strategy can be performed with IMV (Zhang et al., 2015; Fan, Brodie \& Slutsky,

221 2018), but it is impossible under NIV. Furthermore, the use of NIV or HFNC can delay IMV,

222 leading to emergency or more unstable intubations (Brochard, 2003). Thus, IMV should be

223 considered as early as possible if the COD reaches $30 \mathrm{mmHg} \cdot$ day, without trying NIV or

224 HFNC to delay intubation.

$225 \mathrm{PaO}_{2}$ and its derivatives such as PF ratio are well established risk factor for mortality outcome in 226 patients with ARDS. Thus, PF ratio is used to classify ARDS patients into mild, moderate and 227 severe cases (ARDS Definition Task Force et al., 2012). However, this risk classification system 228 considers only the magnitude of hypoxemia (Cartotto et al., 2016; Dai et al., 2019). Our results 229 suggest that the duration of hypoxemia can be equally important. A strength of our study was 230 that all measurements of $\mathrm{PaO}_{2}$ were collected longitudinally, allowing for the calculation of the 231 area under the $\mathrm{PaO}_{2}$-day curve to derive a novel predictor. Our analysis focused on patients with 232 IMV and found that the predictive performance for survival outcome of COD before intubation 233 was substantially better than $\mathrm{PaO}_{2}$ or the time from admission to intubation. The latter two 234 indices are the two components of COD. The combination of the two indices substantially 235 improves the predictive discrimination for mechanically ventilated patients. Although direct 236 causal inference that the use of IMV to reduce COD can improve survival outcome cannot be 237 established with current analysis, our result identified a modifiable risk factor for survival 
238 outcome. It is reasonable to deduce that reducing COD as early as possible with IMV can be

239 beneficial.

240 Several limitations should be acknowledged in the study. First, the study was retrospective in

241 design, and many unmeasured confounders may exist to influence the choice of respiratory

242 supports (Uddin et al., 2016). The presence of such unmeasured confounders will compromise

243 the effectiveness of the propensity score matching procedure. Second, the use of NIV or HFNC

244 was completely at the discretion of the treating physician. There was no standard protocol in

245 participating hospitals. Thus, it is difficult to determine whether the use of NIV or HFNC could

246 benefit COVID-19 induced ARDS. Third, for patients without IMV, we calculated the COD

247 across all days of hospitalization. This could be biased because the time-dimension was longer

248 than the IMV group. However, since non-IMV group generally did not have oxygen deficit

249 across hospital stay, the COD was substantially lower than the IMV group. Finally, we only

250 included broad categories of comorbidity burden in our analysis (i.e., respiratory system,

251 cardiovascular system), because the retrospective design of the study did not allow detailed

252 information for the calculation of the Elixhauser's comorbidity index. It is well known that

253 Elixhauser's comorbidity index is a good quantity for risk stratification of hospitalized

254 patients(Elixhauser et al., 1998). However, this index is designed to work with ICD-9-CM codes

255 in administrative database, which is not applicable to data collected in retrospective studies.

\section{Conclusions}

257 In conclusion, the study developed a novel predictor COD, which considered both magnitude

258 and duration of hypoxemia, to assist the timing of IMV in patients with COVID-19. We suggest 
259 IMV should be the preferred ventilatory support once the COD reaches $30 \mathrm{mmHg} \cdot \mathrm{day}$, as

260 mortality increases beyond this value. 


\section{Figure legends}

263 Figure 1. Schematic illustration of the Calculation of cumulative oxygen deficit (COD). The

$264 \mathrm{COD}$ was calculated as the difference of the areas under the reference curve and the $\mathrm{PaO}_{2}$-day

265 curve (the light green area in the figure).

266 Figure 2. Alluvium plot showing the transitions of respiratory supports over time.

267 Figure 3. Time-dependent AUCs for cumulative oxygen deficit, $\mathrm{PaO}_{2}$ and the time from

268 admission to intubation. The AUC of cumulative oxygen deficit was substantially higher than the

269 other two indices from day 14 to 24. 
Alhazzani W, Møller MH, Arabi YM, Loeb M, Gong MN, Fan E, Oczkowski S, Levy MM, Derde L, Dzierba A, Du B, Aboodi M, Wunsch H, Cecconi M, Koh Y, Chertow DS, Maitland K, Alshamsi F, Belley-Cote E, Greco M, Laundy M, Morgan JS, Kesecioglu J, McGeer A, Mermel L, Mammen MJ, Alexander PE, Arrington A, Centofanti JE, Citerio G, Baw B, Memish ZA, Hammond N, Hayden FG, Evans L, Rhodes A 2020. Surviving Sepsis Campaign: guidelines on the management of critically ill adults with Coronavirus Disease 2019 (COVID-19). Intensive care medicine 44:1691-34. DOI: 10.1007/s00134-020-060225.

Alraddadi BM, Qushmaq I, Al-Hameed FM, Mandourah Y, Almekhlafi GA, Jose J, Al-Omari A, Kharaba A, Almotairi A, Khatib Al K, Shalhoub S, Abdulmomen A, Mady A, Solaiman O, Al-Aithan AM, Al-Raddadi R, Ragab A, Balkhy HH, Harthy Al A, Sadat M, Tlayjeh H, Merson L, Hayden FG, Fowler RA, Arabi YM, Saudi Critical Care Trials Group 2019. Noninvasive ventilation in critically ill patients with the Middle East respiratory syndrome. Influenza and other respiratory viruses 13:382-390. DOI: 10.1111/irv.12635.

ARDS Definition Task Force, Ranieri VM, Rubenfeld GD, Thompson BT, Ferguson ND, Caldwell E, Fan E, Camporota L, Slutsky AS 2012. Acute respiratory distress syndrome: the Berlin Definition. In: 2526-2533. DOI: 10.1001/jama.2012.5669.

Barr J, Fraser GL, Puntillo K, Ely EW, Gélinas C, Dasta JF, Davidson JE, Devlin JW, Kress JP, Joffe AM, Coursin DB, Herr DL, Tung A, Robinson BRH, Fontaine DK, Ramsay MA, Riker RR, Sessler CN, Pun B, Skrobik Y, Jaeschke R, American College of Critical Care Medicine 2013. Clinical practice guidelines for the management of pain, agitation, and delirium in adult patients in the intensive care unit. In: 263-306. DOI: 10.1097/CCM.0b013e3182783b72.

Bellani G, Laffey JG, Pham T, Fan E, Brochard L, Esteban A, Gattinoni L, van Haren F, Larsson A, McAuley DF, Ranieri M, Rubenfeld G, Thompson BT, Wrigge H, Slutsky AS, Pesenti A, LUNG SAFE Investigators, ESICM Trials Group 2016. Epidemiology, Patterns of Care, and Mortality for Patients With Acute Respiratory Distress Syndrome in Intensive Care Units in 50 Countries. JAMA 315:788-800. DOI: 10.1001/jama.2016.0291.

Brochard L 2003. Mechanical ventilation: invasive versus noninvasive. The European respiratory journal. Supplement 47:31s-37s. DOI: 10.1183/09031936.03.00050403.

Brochard L, Lefebvre J-C, Cordioli RL, Akoumianaki E, Richard J-CM 2014. Noninvasive ventilation for patients with hypoxemic acute respiratory failure. Seminars in respiratory and critical care medicine 35:492-500. DOI: 10.1055/s-0034-1383863.

Cartotto R, Li Z, Hanna S, Spano S, Wood D, Chung K, Camacho F 2016. The Acute Respiratory Distress Syndrome (ARDS) in mechanically ventilated burn patients: An analysis of risk factors, clinical features, and outcomes using the Berlin ARDS definition. Burns : journal of the International Society for Burn Injuries 42:1423-1432. DOI: 10.1016/j.burns.2016.01.031.

Chang W, Sun Q, Peng F, Xie J, Qiu H, Yang Y 2020. Validation of neuromuscular blocking agent use in acute respiratory distress syndrome: a meta-analysis of randomized trials. Critical care (London, England) 24:54-8. DOI: 10.1186/s13054-020-2765-2. 
314 Chawla R, Dixit SB, Zirpe KG, Chaudhry D, Khilnani GC, Mehta Y, Khatib KI, Jagiasi BG,

315

316

317

318

319

320

321

322

323

324

325

326

327

328

329

330

331

332

333

334

335

336

337

338

339

340

341

342

343

344

345

346

347

348

349

350

351

352

353

354

355

356

357

358

Chanchalani G, Mishra RC, Samavedam S, Govil D, Gupta S, Prayag S, Ramasubban S, Dobariya J, Marwah V, Sehgal I, Jog SA, Kulkarni AP 2020. ISCCM Guidelines for the Use of Non-invasive Ventilation in Acute Respiratory Failure in Adult ICUs. Indian journal of critical care medicine : peer-reviewed, official publication of Indian Society of Critical Care Medicine 24:S61-S81. DOI: 10.5005/jp-journals-10071-G23186.

Collins J-A, Rudenski A, Gibson J, Howard L, O'Driscoll R 2015. Relating oxygen partial pressure, saturation and content: the haemoglobin-oxygen dissociation curve. Breathe (Sheffield, England) 11:194-201. DOI: 10.1183/20734735.001415.

Cressoni M, Gotti M, Chiurazzi C, Massari D, Algieri I, Amini M, Cammaroto A, Brioni M, Montaruli C, Nikolla K, Guanziroli M, Dondossola D, Gatti S, Valerio V, Vergani GL, Pugni P, Cadringher P, Gagliano N, Gattinoni L 2016. Mechanical Power and Development of Ventilator-induced Lung Injury. Anesthesiology 124:1100-1108. DOI: 10.1097/ALN.0000000000001056.

Dai Q, Wang S, Liu R, Wang H, Zheng J, Yu K 2019. Risk factors for outcomes of acute respiratory distress syndrome patients: a retrospective study. Journal of thoracic disease 11:673-685. DOI: $10.21037 /$ jtd.2019.02.84.

Elixhauser A, Steiner C, Harris DR, Coffey RM 1998. Comorbidity measures for use with administrative data. Medical care 36:8-27. DOI: 10.1097/00005650-199801000-00004.

Fan E, Brodie D, Slutsky AS 2018. Acute Respiratory Distress Syndrome: Advances in Diagnosis and Treatment. JAMA 319:698-710. DOI: 10.1001/jama.2017.21907.

Herasevich V, Tsapenko M, Kojicic M, Ahmed A, Kashyap R, Venkata C, Shahjehan K, Thakur SJ, Pickering BW, Zhang J, Hubmayr RD, Gajic O 2011. Limiting ventilator-induced lung injury through individual electronic medical record surveillance. Critical care medicine 39:34-39. DOI: 10.1097/CCM.0b013e3181fa4184.

Jakob SM, Ruokonen E, Grounds RM, Sarapohja T, Garratt C, Pocock SJ, Bratty JR, Takala J, Dexmedetomidine for Long-Term Sedation Investigators 2012. Dexmedetomidine vs midazolam or propofol for sedation during prolonged mechanical ventilation: two randomized controlled trials. JAMA 307:1151-1160. DOI: 10.1001/jama.2012.304.

Jin Y-H, Cai L, Cheng Z-S, Cheng H, Deng T, Fan Y-P, Fang C, Huang D, Huang L-Q, Huang Q, Han Y, Hu B, Hu F, Li B-H, Li Y-R, Liang K, Lin L-K, Luo L-S, Ma J, Ma L-L, Peng ZY, Pan Y-B, Pan Z-Y, Ren X-Q, Sun H-M, Wang Y, Wang Y-Y, Weng H, Wei C-J, Wu DF, Xia J, Xiong Y, Xu H-B, Yao X-M, Yuan Y-F, Ye T-S, Zhang X-C, Zhang Y-W, Zhang Y-G, Zhang H-M, Zhao Y, Zhao M-J, Zi H, Zeng X-T, Wang Y-Y, Wang X-H, , for the Zhongnan Hospital of Wuhan University Novel Coronavirus Management and Research Team, Evidence-Based Medicine Chapter of China International Exchange and Promotive Association for Medical and Health Care (CPAM) 2020. A rapid advice guideline for the diagnosis and treatment of 2019 novel coronavirus $(2019-\mathrm{nCoV})$ infected pneumonia (standard version). Military Medical Research 7:4-23. DOI: 10.1186/s40779-020-0233-6.

Kamarudin AN, Cox T, Kolamunnage-Dona R 2017. Time-dependent ROC curve analysis in medical research: current methods and applications. BMC medical research methodology 17:53.

Murray MJ, DeBlock H, Erstad B, Gray A, Jacobi J, Jordan C, McGee W, McManus C, Meade M, Nix S, Patterson A, Sands MK, Pino R, Tescher A, Arbour R, Rochwerg B, Murray CF, Mehta S 2016. Clinical Practice Guidelines for Sustained Neuromuscular Blockade in the

PeerJ reviewing PDF | (2020:09:52971:2:1:NEW 13 Nov 2020) 
Adult Critically Ill Patient. Critical care medicine 44:2079-2103. DOI: 10.1097/CCM.0000000000002027.

Novel Coronavirus Pneumonia Emergency Response Epidemiology Team 2020. [The epidemiological characteristics of an outbreak of 2019 novel coronavirus diseases (COVID19) in China]. Zhonghua liu xing bing xue za zhi = Zhonghua liuxingbingxue zazhi 41:145151. DOI: 10.3760/cma.j.issn.0254-6450.2020.02.003.

Phua J, Weng L, Ling L, Egi M, Lim C-M, Divatia JV, Shrestha BR, Arabi YM, Ng J, Gomersall CD, Nishimura M, Koh Y, Du B, Asian Critical Care Clinical Trials Group 2020. Intensive care management of coronavirus disease 2019 (COVID-19): challenges and recommendations. The Lancet. Respiratory medicine. DOI: 10.1016/S2213-2600(20)301612.

Ruan Q, Yang K, Wang W, Jiang L, Song J 2020. Clinical predictors of mortality due to COVID-19 based on an analysis of data of 150 patients from Wuhan, China. Intensive care medicine 368:m641-3. DOI: 10.1007/s00134-020-05991-x.

Uddin MJ, Groenwold RHH, Ali MS, de Boer A, Roes KCB, Chowdhury MAB, Klungel OH 2016. Methods to control for unmeasured confounding in pharmacoepidemiology: an overview. International journal of clinical pharmacy 38:714-723. DOI: 10.1007/s11096016-0299-0.

Wang D, Hu B, Hu C, Zhu F, Liu X, Zhang J, Wang B, Xiang H, Cheng Z, Xiong Y, Zhao Y, Li Y, Wang X, Peng Z 2020. Clinical Characteristics of 138 Hospitalized Patients With 2019 Novel Coronavirus-Infected Pneumonia in Wuhan, China. JAMA. DOI: 10.1001/jama.2020.1585.

Wu Z, McGoogan JM 2020. Characteristics of and Important Lessons From the Coronavirus Disease 2019 (COVID-19) Outbreak in China: Summary of a Report of 72314 Cases From the Chinese Center for Disease Control and Prevention. JAMA. DOI: 10.1001/jama.2020.2648.

Yang X, Yu Y, Xu J, Shu H, Xia J, Liu H, Wu Y, Zhang L, Yu Z, Fang M, Yu T, Wang Y, Pan S, Zou X, Yuan S, Shang Y 2020. Clinical course and outcomes of critically ill patients with SARS-CoV-2 pneumonia in Wuhan, China: a single-centered, retrospective, observational study. The Lancet. Respiratory medicine. DOI: 10.1016/S2213-2600(20)30079-5.

Zhang Z, Gayle AA, Wang J, Zhang H, Cardinal-Fernández P 2017. Comparing baseline characteristics between groups: an introduction to the CBCgrps package. Annals of translational medicine 5:484-484. DOI: 10.21037/atm.2017.09.39.

Zhang Z, Hu X, Zhang X, Zhu X, Chen L, Zhu L, Hu C, Du B, China Critical Care Clinical Trials Group (CCCCTG) 2015. Lung protective ventilation in patients undergoing major surgery: a systematic review incorporating a Bayesian approach. BMJ Open 5:e007473. DOI: 10.1136/bmjopen-2014-007473. 


\section{Table $\mathbf{1}$ (on next page)}

Table 1 Comparison between patients with and without invasive mechanical ventilation

Comparison between patients with and without invasive mechanical ventilation 
1 Table 1 Comparison between patients with and without invasive mechanical ventilation

\begin{tabular}{|c|c|c|c|c|}
\hline Variables & Total $(n=111)$ & No IMV $(n=80)$ & $\operatorname{IMV}(n=31)$ & $p$ \\
\hline Age, Median (IQR) & $57(45.5,68.5)$ & $56(40,67.25)$ & $64(54.5,70.5)$ & 0.076 \\
\hline Sex, male (\%) & $60(55)$ & $39(50)$ & $21(68)$ & 0.143 \\
\hline \multicolumn{5}{|l|}{ Comorbidities } \\
\hline Respiratory system, n (\%) & $18(16)$ & $13(16)$ & $5(16)$ & 1 \\
\hline Cardiovascular system, n (\%) & $41(37)$ & $29(36)$ & $12(39)$ & 0.983 \\
\hline Smoking history, $\mathrm{n}(\%)$ & $2(2)$ & $1(1)$ & $1(3)$ & 0.482 \\
\hline $\begin{array}{l}\mathrm{PaCO} 2(\mathrm{mmHg}), \text { Median } \\
\text { (IQR) }\end{array}$ & $43(39,47.5)$ & $44(41,48)$ & $39(36,45)$ & 0.051 \\
\hline $\mathrm{PaO} 2$ (mmHg), Median (IQR) & $82(60,120)$ & $90.5(68,125.25)$ & $62(49,89)$ & $\begin{array}{l}< \\
0.001\end{array}$ \\
\hline $\mathrm{pH}$, Median (IQR) & $\begin{array}{l}7.42(7.35 \\
7.44)\end{array}$ & $7.40(7.35,7.43)$ & $\begin{array}{l}7.44(7.38, \\
7.47)\end{array}$ & 0.006 \\
\hline $\mathrm{BE}(\mathrm{mmol} / \mathrm{l})$, Median (IQR) & $2.4(-2.05,5.1)$ & $2.35(-2.57,5.1)$ & $2.4(0.2,5.2)$ & 0.342 \\
\hline $\begin{array}{l}\text { Lactate }(\mathrm{mmol} / \mathrm{I}), \text { Median } \\
\text { (IQR) }\end{array}$ & $1.9(1.3,3)$ & $1.7(1.1,2.85)$ & $2.5(1.7,3.1)$ & 0.036 \\
\hline PF (mmHg), Median (IQR) & $\begin{array}{l}224.32(106.14, \\
348.02)\end{array}$ & $\begin{array}{l}250.05(194.14, \\
363.64)\end{array}$ & $\begin{array}{l}111.25(71.98, \\
200.27)\end{array}$ & $\begin{array}{l}< \\
0.001 \\
\end{array}$ \\
\hline CRP (mg/dl), Median (IQR) & $8.9(2.75,53.2)$ & $5.5(1.78,35.83)$ & $\begin{array}{l}19.5(9.85 \\
78.05)\end{array}$ & $\begin{array}{l}< \\
0.001\end{array}$ \\
\hline $\begin{array}{l}\text { Lymphocyte count }\left(\times 10^{9} / L\right. \\
\text { ), Median (IQR) }\end{array}$ & $\begin{array}{l}0.78(0.28, \\
0.86)\end{array}$ & $0.78(0.43,0.89)$ & $\begin{array}{l}0.43(0.28, \\
0.66)\end{array}$ & 0.005 \\
\hline $\begin{array}{l}\text { COD (mmHg · day), Median } \\
(\text { IQR) }\end{array}$ & $\begin{array}{l}-50.38(-827.91, \\
72.67)\end{array}$ & $\begin{array}{l}-231.68(- \\
1040.78,119.83) \\
\end{array}$ & $\begin{array}{l}-6.87(-29.36, \\
52.38) \\
\end{array}$ & 0.018 \\
\hline COD, n (\%) & & & & $\begin{array}{l}< \\
0.001\end{array}$ \\
\hline$<0$ (mmHg $\cdot$ day $)$ & $56(50)$ & $49(61)$ & $7(23)$ & \\
\hline 0-30 (mmHg · day) & $14(13)$ & $3(4)$ & $11(35)$ & \\
\hline $30-50(\mathrm{mmHg} \cdot$ day $)$ & $9(8)$ & $5(6)$ & $4(13)$ & \\
\hline$>50(\mathrm{mmHg} \cdot$ day $)$ & $32(29)$ & $23(29)$ & $9(29)$ & \\
\hline $\begin{array}{l}\text { Hospital LOS (days), Mean } \pm \\
\text { SD }\end{array}$ & $26.55 \pm 11.78$ & $26.1 \pm 11.35$ & $27.7 \pm 12.97$ & 0.548 \\
\hline Mortality, n (\%) & $22(20)$ & $13(16)$ & $9(29)$ & 0.211 \\
\hline
\end{tabular}

2 Abbreviations: LOS: length of stay; SD: standard deviation; COD: cumulative oxygen deficit; CRP:

3 C-reactive protein; IQR: interquartile range; BE: base excess

4 


\section{Table 2 (on next page)}

Table 2 Multivariable Cox regression model to explore the independent association of cumulative oxygen deficit and hazard of death in patients with invasive mechanical ventilation

Abbreviations: COD: cumulative oxygen deficit; CRP: C-reactive protein; IQR: interquartile range; $\mathrm{BE}$ : base excess; $\mathrm{HR}$ : hazard ratio; $\mathrm{Cl}$ : confidence interval 
1 Table 2 Multivariable Cox regression model to explore the independent association of

2 cumulative oxygen deficit and hazard of death in patients with invasive mechanical ventilation

\begin{tabular}{|l|l|l|}
\hline & $\mathrm{HR}[95 \% \mathrm{Cl}]$ & $\mathrm{p}$ \\
\hline $\mathrm{COD}(<0$ as reference) & 1 & \\
\hline $0-30$ & $1.45[0.98,3.47]$ & 0.052 \\
\hline $30-50$ & $3.79[2.57,16.93]$ & 0.037 \\
\hline$>50$ & $10.45[1.28,85.37]$ & 0.029 \\
\hline Time from admission to intubation & $0.78[0.59,1.03]$ & 0.078 \\
\hline Age & $1.20[1.00,1.44]$ & 0.056 \\
\hline Sex (female as reference) & $9.84[0.43,225.59]$ & 0.152 \\
\hline $\mathrm{PaCO} 2$ & $0.85[0.60,1.19]$ & 0.344 \\
\hline $\mathrm{PaO2}$ & $1.00[0.97,1.03]$ & 0.939 \\
\hline $\mathrm{pH}$ & $0.70[0.44,1.13]$ & 0.144 \\
\hline $\mathrm{BE}$ & $1.89[0.70,5.08]$ & 0.206 \\
\hline $\mathrm{CRP}$ & $0.98[0.94,1.01]$ & 0.233 \\
\hline Lymphocyte count & $2.21[0.04,115.48]$ & 0.695 \\
\hline
\end{tabular}

3 Abbreviations: COD: cumulative oxygen deficit; CRP: C-reactive protein; IQR: interquartile

4 range; $\mathrm{BE}$ : base excess; $\mathrm{HR}$ : hazard ratio; $\mathrm{Cl}$ : confidence interval

5

6

7 


\section{Table 3 (on next page)}

Table 3 Factors associated with use of IMV

Abbreviations: CRP: C-reactive protein; HR: hazard ratio; $\mathrm{Cl}$ : confidence interval 
1 Table 3 Factors associated with use of IMV

\begin{tabular}{|l|l|l|}
\hline Variables & $\mathrm{HR}[95 \% \mathrm{Cl}]$ & $\mathrm{p}$ \\
\hline $\mathrm{PaO} 2$ (for every 10-mmHg increase) & $0.91[0.84,0.99]$ & 0.022 \\
\hline $\mathrm{PaCO} 2$ & $1.02[0.98,1.06]$ & 0.337 \\
\hline Age & $1.02[0.99,1.04]$ & 0.235 \\
\hline $\mathrm{pH}$ (for every 0.01 increase) & $1.02[0.96,1.09]$ & 0.565 \\
\hline $\mathrm{CRP}$ & $1.00[0.99,1.01]$ & 0.824 \\
\hline Lymphocyte count & $0.27[0.09,0.81]$ & 0.020 \\
\hline Lactate & $1.56[1.17,2.08]$ & 0.003 \\
\hline
\end{tabular}

2 Abbreviations: CRP: C-reactive protein; HR: hazard ratio; $\mathrm{Cl}$ : confidence interval 3 


\section{Figure 1}

Figure 1. Schematic illustration of the Calculation of cumulative oxygen deficit (COD).

The COD was calculated as the difference of the areas under the reference curve and the $\mathrm{PaO}_{2}$-day curve (the light green area in the figure). 


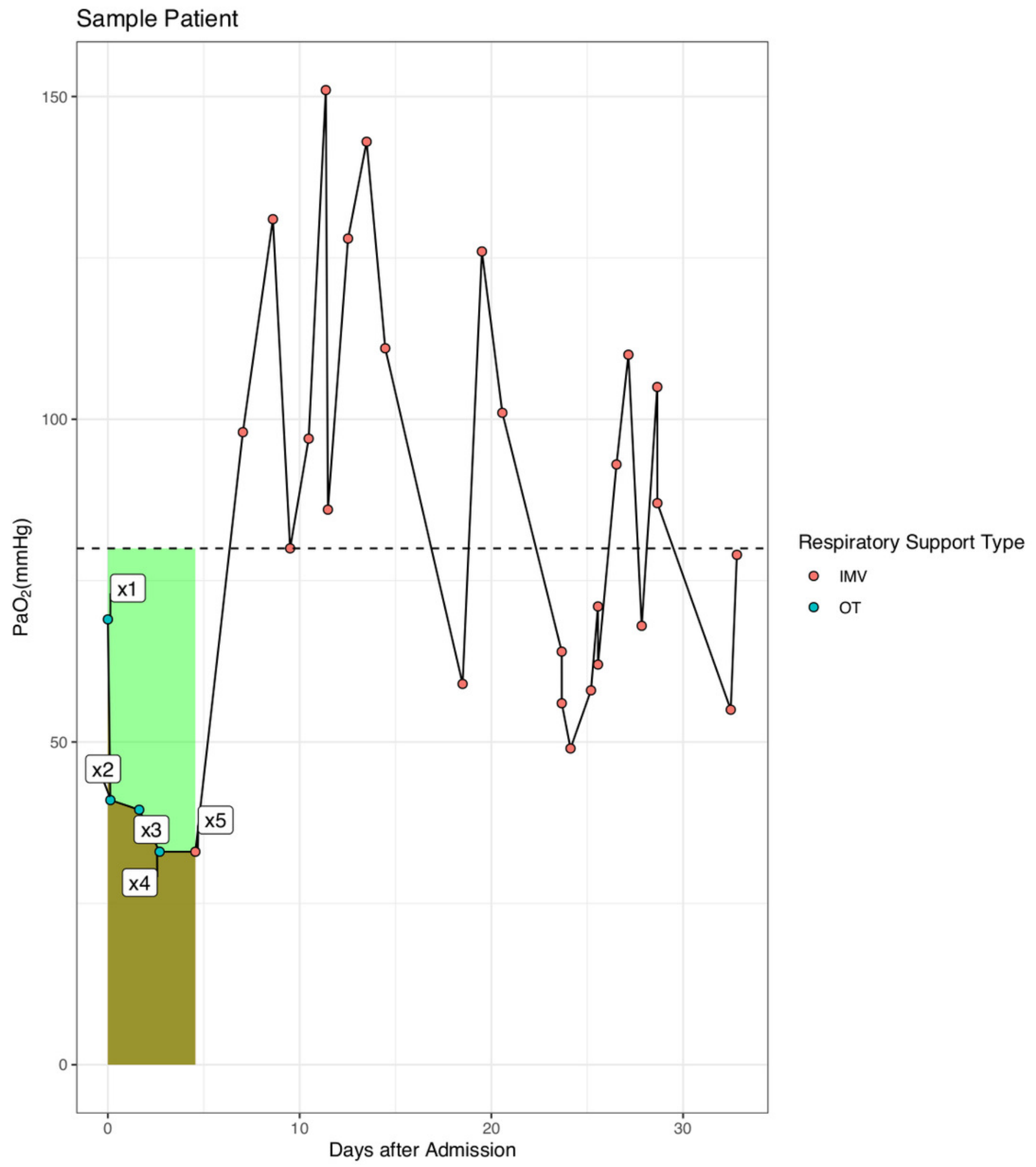


Figure 2

Figure 2. Alluvial plot showing the transitions of respiratory supports over time.

Figure 2. Alluvial plot showing the transitions of respiratory supports over time.

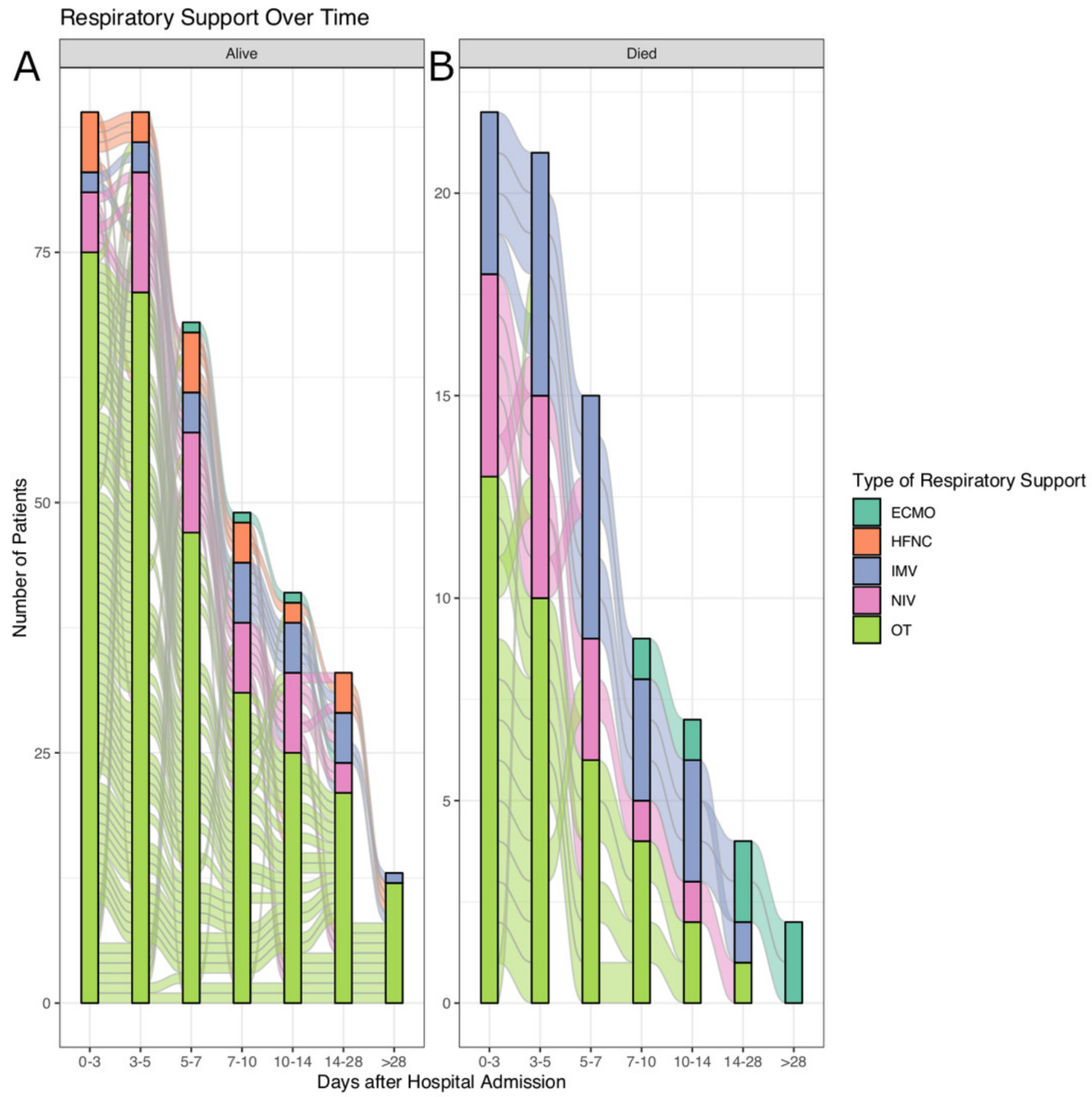


Figure 3

Figure 3. Time-dependent AUCs for cumulative oxygen deficit, $\mathrm{PaO}_{2}$ and the time from admission to intubation.

The AUC of cumulative oxygen deficit was significantly higher than the other two indices from day 14 to 24 .

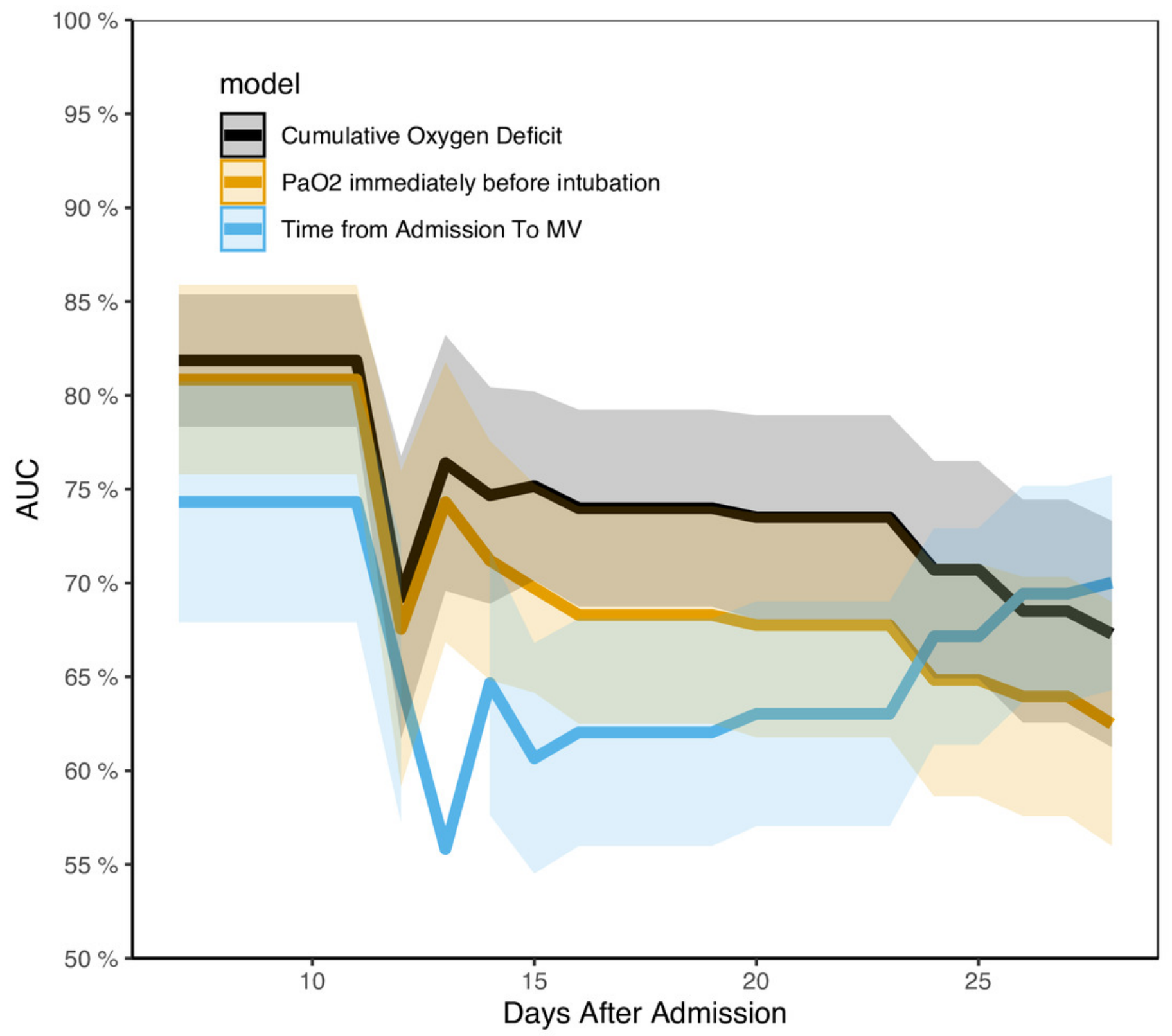

